\title{
Interregional Disparity and Convergence Tendency: An Empirical Study of TFP Growth in China
}

\author{
Yanqing Jiang \\ School of Economics and Finance, Shanghai International Studies University, Shanghai, P. R. China \\ Correspondence: Yanqing Jiang, School of Economics and Finance, Shanghai International Studies University, No. \\ 1550 Wenxiang Rd., Shanghai 201620, P. R. China
}

Received: April 11, 2014

Accepted: April 21, 2014

Available online: June 11, 2014

doi:10.11114/aef.v1i2.386

URL: http://dx.doi.org/10.11114/aef.v1i2.386

\begin{abstract}
This paper presents an empirical analysis to improve our understanding of the catch-up and convergence tendencies of total factor productivity (TFP) growth across the Chinese provinces over 2003-2012. After controlling for the province heterogeneity, our regression results show that the Chinese provinces exhibit significant conditional convergence in TFP growth over the sample period. This indicates that province-specific factors play an important role in determining provincial TFP growth. Economic policies conducive to faster TFP growth should thus be directed to the relevant factors underlying the province heterogeneity. This paper suggests that openness to international economic activities and human capital accumulation are two important factors that promote TFP growth, both of which rely on a salutary social infrastructure.
\end{abstract}

Keywords: economic growth, interregional disparity, total factor productivity, convergence, technology spillover

\section{Introduction}

\subsection{Motivation}

China has been one of the fastest growing economies in the world in the past 35 years. However, different regions in China have markedly different growth rates, and as a result, show substantial disparities in per capita income levels. ${ }^{1}$ What are the key driving forces behind the uneven growth? Is it growth of total factor productivity (TFP hereinafter) or factor accumulation that has mainly shaped the uneven regional growth? A finding of an important role of TFP in promoting regional growth, for example, suggests that the mere channeling of capital investment into lagging provinces may not ensure their faster growth unless it is associated with TFP growth (Islam and Dai, 2007). It is important for policymakers to gauge the relative contributions of capital accumulation and TFP growth to income growth as this information is useful in making necessary policies to counteract the rising trend of interregional disparity in China.

The main objective of this paper is to explore the characteristics of interregional TFP disparity in China and to provide an empirical analysis that will enrich our understanding of the catch-up and convergence processes of the Chinese regions regarding TFP. Our empirical analysis shows that province-specific factors play an important role in determining provincial TFP growth. After controlling for the effects of province-specific factors, our regression results show that the Chinese provinces exhibited significant conditional convergence in TFP growth. Economic policies beneficial to faster TFP growth should thus be directed to relevant factors underlying the province heterogeneity term in our regression equation. Our analysis also suggests that openness to international economic activities and human capital accumulation are two important factors that promote TFP growth, both of which rely on a salutary social infrastructure.

\subsection{Organization}

The rest of this paper is organized as follows. In Section 2, we present the model and derive the baseline regression equation on which our later empirical analysis will be based. In Section 3, we present and analyze results from

\footnotetext{
1 Many studies have explored the various driving forces behind economic growth and interregional inequality in China. See, for example, Jian, Sachs, and Warner (1996), Yao (1997), Yang (1999), DaCosta and Carroll (2001), Demurger (2001), Demurger et al. (2002), Huang, Kuo, and Kao (2003), Zhang and Zhang (2003), Kanbur and Zhang (2005), Wan, Lu, and Chen (2007), Zhu, Lai, and Fu (2008), Jiang (2010, 2011), and Fleisher, Li, and Zhao (2010).
} 
regressions based on a simplified version of our baseline regression equation with no human capital variables appearing as explanatory variables. In Section 4, we calculate regional per worker human capital stocks and run regressions controlling for human capital variables. Regression results are presented and analyzed accordingly. In Section 5 we provide an analysis of the province heterogeneity that affects provincial TFP growth. Section 6 contains a summary and conclusion.

\section{The Model}

\subsection{Decomposition of Per Worker Output Growth}

In this section we derive the baseline regression specification on which our subsequent empirical analysis will be based. To account for growth in per worker output, we assume a Cobb-Douglas aggregate production function with Hicks-neutral TFP. For province $i$ at time $t$ we have

$$
Y_{i}(t)=A_{i}(t) K_{i}(t)^{\alpha} H_{i}(t)^{\beta} L_{i}(t)^{1-\alpha-\beta}
$$

where $Y$ is total output, $K$ is the stock of physical capital, $H$ is the stock of human capital, $L$ is the number of workers, and $A$ is the Hicks-neutral TFP. The intensive form in per worker terms is then

$$
y_{i}(t)=A_{i}(t) k_{i}(t)^{\alpha} h_{i}(t)^{\beta}
$$

where $y \equiv Y / L, \quad k \equiv K / L$, and $h \equiv H / L$ are output per worker, physical capital per worker, and human capital per worker respectively. It follows that for province $i$ at time $t$ growth in per worker output can be written as

$$
d \ln y_{i}(t) / d t=\alpha\left(d \ln k_{i}(t) / d t\right)+\beta\left(d \ln h_{i}(t) / d t\right)+d \ln A_{i}(t) / d t
$$

\subsection{The Modeling of TFP Growth}

We further assume that growth of TFP for province $i$ at time $t$ is determined by

$$
d \ln A_{i}(t) / d t=\lambda\left[\ln A^{F}(t)-\ln A_{i}(t)\right]+\xi_{i}
$$

$A^{F}(t)$ denotes China's frontier level of TFP at time $t$. $\xi_{i}$ denotes an unobserved time-constant province heterogeneity that affects TFP growth. Therefore, equation (4) describes the convergence tendency of the Chinese provinces in the process of TFP growth, and the parameter $\lambda$ measures the speed of (conditional) convergence of provincial TFP: the farther the provincial TFP lags behind the national frontier level of TFP at time $t$, the faster the provincial TFP tends to grow at time $t$. It then follows that

where $\tau=t_{2}-t_{1}$. For a variable $\mathrm{x}$, define $\Delta x\left(t_{1}\right) \equiv x\left(t_{2}\right)-x\left(t_{1}\right)$, then

$$
\ln A_{i}\left(t_{2}\right)=e^{-\lambda \tau} \ln A_{i}\left(t_{1}\right)+\left(1-e^{-\lambda \tau}\right) \xi_{i} / \lambda+e^{-\lambda t_{2}} \int_{t_{1}}^{t_{2}} \lambda e^{\lambda t} \ln A^{F}(t) d t
$$

$$
\Delta \ln y_{i}\left(t_{1}\right)=\alpha \Delta \ln k_{i}\left(t_{1}\right)+\beta \Delta \ln h_{i}\left(t_{1}\right)+\Delta \ln A_{i}\left(t_{1}\right)
$$

Inserting equation (5) into equation (6) gives us

$$
\begin{gathered}
\Delta \ln y_{i}\left(t_{1}\right)=\alpha \Delta \ln k_{i}\left(t_{1}\right)+\beta \Delta \ln h_{i}\left(t_{1}\right)-\left(1-e^{-\lambda \tau}\right) \ln A_{i}\left(t_{1}\right) \\
+\left(1-e^{-\lambda \tau}\right) \xi_{i} / \lambda+e^{-\lambda t_{2}} \int_{t_{1}}^{t_{2}} \lambda e^{\lambda t} \ln A^{F}(t) d t \\
=\alpha \Delta \ln k_{i}\left(t_{1}\right)+\beta \Delta \ln h_{i}\left(t_{1}\right)-\left(1-e^{-\lambda \tau}\right)\left[\ln y_{i}\left(t_{1}\right)-\alpha \ln k_{i}\left(t_{1}\right)-\beta \ln h_{i}\left(t_{1}\right)\right] \\
+\left(1-e^{-\lambda \tau}\right) \xi_{i} / \lambda+e^{-\lambda t_{2}} \int_{t_{1}}^{t_{2}} \lambda e^{\lambda t} \ln A^{F}(t) d t
\end{gathered}
$$

The second equality immediately follows the production function in (2). In traditional panel data notations, equation (7) can be rewritten as the following regression model:

$$
\Delta q_{i t}=\alpha \Delta m_{i t}+\beta \Delta b_{i t}-\varphi\left(q_{i t}-\alpha m_{i t}-\beta b_{i t}\right)+c_{i}+\eta_{t}+\varepsilon_{i t}
$$

where the time subscript $t=1, \ldots,(10-\tau)$. Letters $q, m$, and $b$ denote logs of variables $y, k$ and $h$ respectively. $\alpha, \beta$ and $\varphi$ are parameters to be estimated with $\varphi \equiv\left(1-e^{-\lambda \tau}\right) . c_{i}$ is a time-constant province-specific latent variable, $\eta_{t}$ is the time intercept, and $\varepsilon_{i t}$ is the zero-mean idiosyncratic error term. In the next two sections, we will use nonlinear least squares methods to estimate the values of the parameters $\alpha, \beta$ and $\varphi$ based on different versions of equation (8).

It should be noted that an alternative approach to examining TFP growth and convergence of the Chinese provinces within the framework of our model can also be applied by running regressions that have the TFP growth $\Delta \ln A_{i t}$ directly as the left-hand side variable. This method involves explicitly calculating TFP as a residual from the production function, which requires an assumed value of the output elasticity of capital $\alpha$ a priori. In contrast, our current method based on equation (8) has the advantage of being able to circumvent the somewhat difficult assumptions to be made on the likely values of $\alpha$. Instead, our current method provides an estimated value for the output elasticity of capital $\alpha$ as a byproduct through a regression based on equation (8). 


\section{Regression Results without Human Capital}

Since in growth empirics calculating human capital has always been a weak spot fraught with measurement difficulties, in this section we first run regressions based on a simplified version of equation (8) without including human capital in the equation (i.e. assuming $\beta=0$ ). We will postpone including human capital in the regression equation until the next section.

Our sample is 29 Chinese province-level regions over the period 2003-2012. ${ }^{2}$ We obtain from the officially published Chinese Statistical Yearbooks series of nominal Gross Regional Product (GRP), GRP indices, and numbers of total employed people for each province, based on which we calculate the values of real GRP for each province. We calculate real per worker output as real GRP divided by the number of total employed people. We obtain annual data on real provincial capital stocks, by following the method of Zhang, Wu, and Zhang (2007), and the provincial real per worker capital stocks can thus be calculated.

Table 1. Single cross section regressions

\begin{tabular}{ccccc}
\hline & $\tau=9$ & (Obs: 29$)$ & Reg. $1-1$ & \multicolumn{2}{c}{$R^{2}=0.5700$} \\
\hline Parameter & Estimate & Std. Err. & \multicolumn{2}{c}{$95 \%$ Conf. Interval } \\
$\alpha$ & 0.447 & 0.084 & 0.273 & 0.620 \\
$\varphi$ & -0.099 & 0.040 & -0.181 & -0.018 \\
\hline & $\tau=9$ & $($ Obs: 29$)$ & Reg. 1-2 & $R^{2}=0.5799$ \\
\hline Parameter & Estimate & Std. Err. & \multicolumn{2}{c}{$95 \%$ Conf. Interval } \\
$\alpha$ & 0.455 & 0.089 & 0.271 & 0.640 \\
$\varphi$ & -0.073 & 0.056 & -0.189 & 0.043 \\
Coef. on $E$ & 0.022 & 0.051 & -0.083 & 0.127 \\
Coef. on $W$ & -0.017 & 0.041 & -0.102 & 0.067 \\
\hline
\end{tabular}

\subsection{Testing Absolute Convergence}

We are first interested in whether there exists absolute convergence in TFP across the Chinese regions over the sample period. To check this, we run a single cross section regression based on equation (8) by setting the time interval $\tau=9$ (years). This is to say the explained variable on the left-hand side is now growth of real regional per worker output over the entire sample period 2003-2012. Major results from the nonlinear least squares method of this single cross section regression is summarized in the upper half of Table 1 (Reg. 1-1). The estimated value of the output elasticity of (physical) capital, $\alpha$, is 0.447 , with a $95 \%$ interval estimate of $[0.273,0.620]$. The estimated value of $\varphi$ is about -0.1 , which is significantly negative at the $5 \%$ significance level. Therefore, we fail to find absolute convergence in TFP across the Chinese regions over 2003-2012. Instead, there exists absolute divergence in TFP across the Chinese regions over the sample period.

\subsection{Testing Club Convergence}

Next, we are also interested in whether there exists 'club convergence' in TFP across the Chinese regions over the sample period. We divide the Mainland China into three zones: the eastern coastal zone, the central zone, and the western zone. The three big zones exhibit systematic differences not only in aspects such as climate and resource endowment, but also in aspects such as culture, policy and exposure to foreign trade and foreign direct investment. In the latter half of Table 1 (Reg. 1-2), we present results of a regression that includes two zone dummy variables, E (for 'east') and $\mathrm{W}$ (for 'west'). $\mathrm{E}=1$ whenever the region is located in the eastern coastal zone and $\mathrm{E}=0$ otherwise, and W $=1$ whenever the region belongs to the western zone and $\mathrm{W}=0$ otherwise. The estimated value of $\alpha$ from this regression is 0.455 , with a $95 \%$ interval estimate of [0.271, 0.640], only very slightly different from its counterpart in Reg. 1-1. The estimated value of $\varphi$ is about -0.07 , slightly higher than that in the previous regression and not significantly negative. Therefore, we fail to detect any 'club convergence' in TFP across the Chinese regions over the sample period. The estimated coefficients on the two zone dummies both have the expected sign, but neither is statistically significant.

\footnotetext{
2 These regions include provinces, ethnic minority autonomous regions, and province-level municipalities, but for convenience we call all of them 'provinces'. Owing to missing data municipality Chongqing and province Hainan are not included in our sample.
} 
Table 2. Pooled cross section regressions

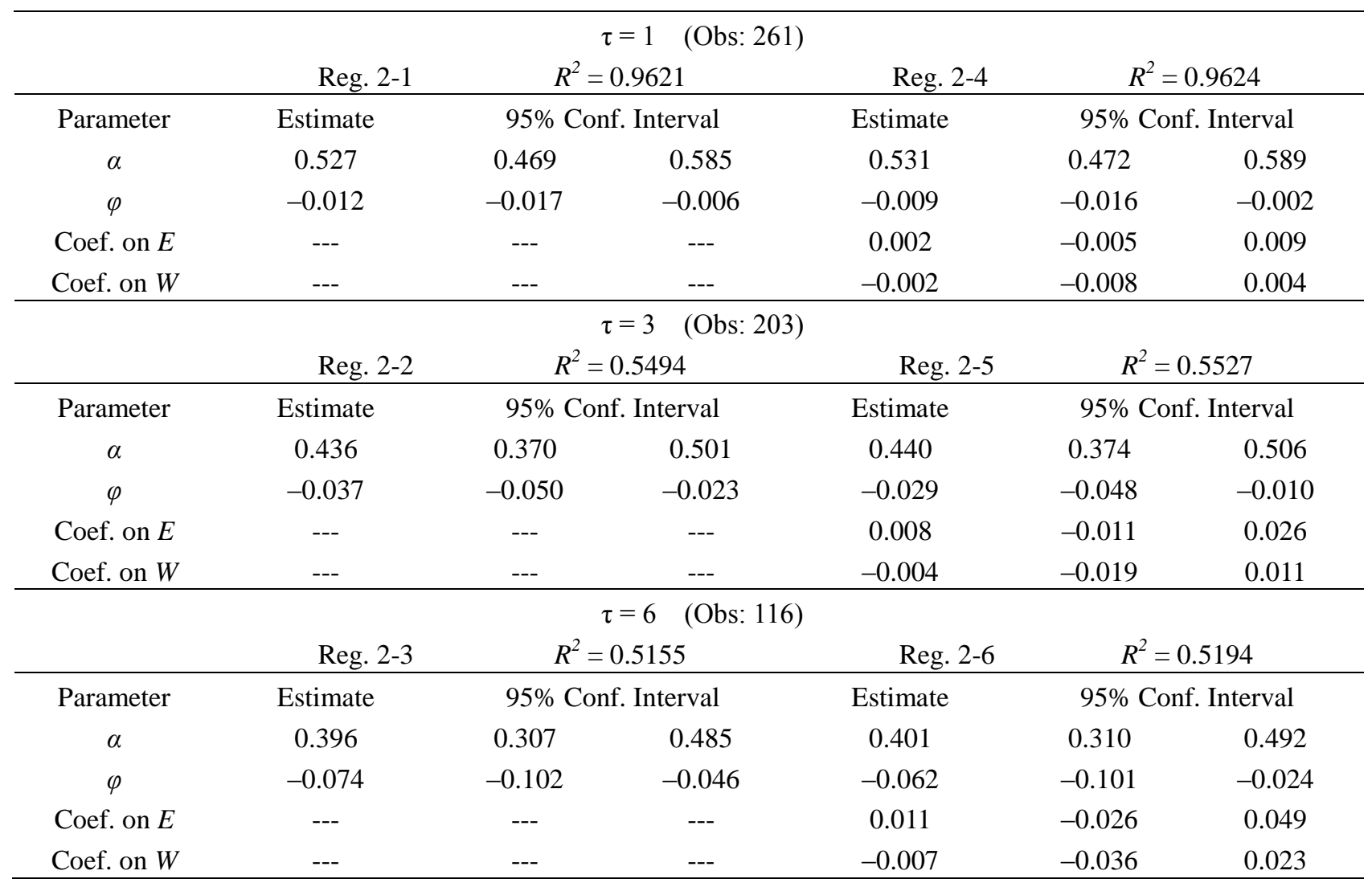

\subsection{More Regressions as Robustness Checks}

To check the robustness of the results above, we now run pooled cross section regressions, each time setting the time interval $\tau=1,3$, and 6 . The regression results are summarized in Table 2. Regressions on the left-hand side of Table 2 do not include the two zone dummies as explanatory variables while, as a comparison, regressions on the right-hand side of Table 2 control for the effects of the zone dummies. All regressions in Table 2 do not control for the effect of the province heterogeneity (for the time being), but they include (a proper number of) time dummy variables to take account of the time-varying intercept in equation (8). There are three major findings from the results in Table 2. First, for the regressions that include the zone dummies, the estimated coefficients on the zone dummies have the expected sign but are practically small and never statistically significant. Nor does the inclusion of the zone dummies alter the estimates of $\alpha$ and $\varphi$ in any significant ways. The point and interval estimates of $\alpha$ and $\varphi$ change only very slightly in response to the inclusion of the zone dummies. Second, the significantly negative values of $\hat{\varphi}$ throughout Table 2 suggest absolute divergence in TFP across the Chinese regions over the sample period. Third, the point estimates of $\alpha$ decreases with $\tau$ going from 1 to 3 to 6 . However, these estimated values of $\alpha$ do not differ very much from those in Table 1.

Next, we are going to see how regression results will change if we now control for the effects of the province heterogeneity. We include province dummy variables for the different provinces to take account of the latent component $c_{i}$ in equation (8). Regression results are summarized in Table 3. The estimated values of $\varphi$ are now all significantly positive. This result suggests that once the province-specific effects are controlled for, the provinces show conditional convergence in TFP over the sample period. The estimated values of the output elasticity of capital, $\alpha$, are somewhat higher than those in Table 2, and are closer to traditionally accepted values for the case of China and its regions, which are around 0.5.3

\footnotetext{
${ }^{3}$ See, for example, Zheng, Hu, and Bigsten (2009) and Brandt and Zhu (2010).
} 
Table 3. Pooled cross section regressions with province dummy variables

\begin{tabular}{ccccc}
\hline & $\tau=1 \quad($ Obs: 261$)$ & Reg. 3-1 & \multicolumn{2}{c}{$R^{2}=0.9725$} \\
\hline Parameter & Estimate & Std. Err. & \multicolumn{2}{c}{$95 \%$ Conf. Interval } \\
$\alpha$ & 0.553 & 0.031 & 0.491 & 0.614 \\
$\varphi$ & 0.092 & 0.031 & 0.031 & 0.154 \\
\hline Parameter & $\tau=3 \quad$ (Obs: 203) & Reg. 3-2 & \multicolumn{2}{c}{$R^{2}=0.8153$} \\
$\alpha$ & Estimate & Std. Err. & $95 \%$ Conf. Interval \\
$\varphi$ & 0.467 & 0.034 & 0.401 & 0.534 \\
\hline & 0.638 & 0.076 & 0.489 & 0.787 \\
\hline Parameter & $\tau=6$ (Obs: 116$)$ & Reg. 3-3 & \multicolumn{2}{c}{$R^{2}=0.9437$} \\
$\alpha$ & Estimate & Std. Err. & 0.405 & 0.576 \\
$\varphi$ & 0.491 & 0.043 & 0.916 & 1.463 \\
\hline
\end{tabular}

\section{Including Human Capital}

\subsection{The Modeling of Human Capital}

In this section, we incorporate human capital into our regression analysis. We use a simple approach to calculating human capital for the Chinese provinces, which follows Hall and Jones (1999) and Jiang (2012, 2014). In calculating per worker human capital $h_{i}$ in a cross-country growth study, Hall and Jones (1999) have assumed that $h_{i}$ is related to educational attainment by $h_{i}=\exp \left[\mu\left(E_{i}\right)\right] . E_{i}$ denotes the average years of schooling attained by a worker in economy $i$. Therefore, the function $\mu(E)$ indicates the relative efficiency of one worker with $E$ years of schooling compared with one with zero schooling $(\mu(0)=0)$. The derivative $\mu^{\prime}(E)$ is the return to schooling estimated in a Mincerian wage regression (Mincer, 1974). In those previous literature, $\mu(E)$ is assumed to be piecewise linear, with the rate of return being 13.4 percent, 10.1 percent and 6.8 percent respectively for schooling of the first four years, the second four years, and that beyond the eighth year. These rates of return are all based on Psacharopoulos (1994)'s survey of evidence from many countries on return-to-schooling estimates. The rate for the first four years, 13.4 percent, corresponds to the average return to an additional year of schooling in sub-Saharan Africa. The rate for the second four years, 10.1 percent, is the average return to an additional year of schooling worldwide, while that for schooling above the eighth year, 6.8 percent, is taken from the average return to an additional year in the OECD.

In this paper, our measure of per worker human capital of province $i$ at time $t$, denoted $h_{i t}$, is constructed as that in Jiang (2014)

$$
h_{i t}=\left(1 / L_{i t}^{*}\right) \sum_{j} h^{j} L_{i t}^{j}
$$

where $L_{i t}^{*}$ is the sum of the $L_{i t}^{j}$ 's (where $j=\mathrm{a}, \mathrm{b}, \mathrm{c}, \mathrm{d}, \mathrm{e}$ ). $L_{i t}^{*}$ denotes province $i$ 's population aged six and above at time $t$. We divide $L_{i t}^{*}$ into five groups by educational attainment: group a through group e. $L_{i t}^{a}$ denotes the total number of people aged six and above who have received zero schooling. $L_{i t}^{b}$ through $L_{i t}^{e}$ respectively denote the total number of people aged six and above who have received schooling up to the primary school level, the junior secondary school level, the senior secondary school level, and the university and higher level. ${ }^{4} h^{a}$ through $h^{e}$ are per worker human capital in each of the five groups respectively. Therefore, the provincial per worker human capital $h_{i t}$ is now a weighted average of the $h^{j}$ 's, with the weights being the $\left(L_{i t}^{j} / L_{i t}^{*}\right)$ 's. Data on these $\left(L_{i t}^{j} / L_{i t}^{*}\right)$ 's for 29 Chinese provinces for each year during 2003-2012 are found in the official publications of the National Statistical Bureau of China. Constructing $h_{i t}$ thus implies the determination of the values of the $h^{j}$ 's.

Obviously $h^{a}=1$ by construction, so that $h_{i}=1$ for a (fictitious) province that has only workers with zero schooling. We set $h^{b}=2, h^{c}=2.6, h^{d}=3.2$, and $h^{e}=4.4$ for all provinces in each year during 2003-2012. These assigned values of the $h^{j}$ 's are calculated exactly according to the aforementioned piecewise linear rates of return to schooling based on Psacharopoulos (1994)'s survey, i.e. 13.4 percent, 10.1 percent and 6.8 percent for schooling of the first four years, the second four years, and beyond the eighth year. ${ }^{5}$

\subsection{Regressions with Human Capital Considered}

Results of regressions parallel to those in Tables 1 and 2 but including human capital are summarized in Table 4 . There

\footnotetext{
4 This five-group division is performed on the provincial population aged six and above because of unavailability of data on the distribution of educational attainment in the provincial employed population or working-age population.

${ }^{5}$ Here, in calculating $h^{e}$, we assume that a worker who has completed university or higher level of education has 17 years of schooling on average.
} 
are two important findings. First, the same as before, for the regressions that include the zone dummy variables, the estimated coefficients on the zone dummies have the expected sign but are practically small and never statistically significant. Nor does the inclusion of the zone dummies alter the estimates of the other parameters in any significant ways. The point and interval estimates of $\alpha, \beta$ and $\varphi$ change only very slightly in response to the inclusion of the zone dummies. Second, the estimated values of $\beta$ do not have the expected positive sign, nor are they significantly different from zero. Compared with results in Tables 1 and 2, the inclusion of human capital in the regressions only alters the estimates of $\alpha$ and $\varphi$ very slightly.

Next we run regressions parallel to those in Table 3. These are regressions that include the full set of province dummy variables as explanatory variables to control for the province-specific effects. Regression results are summarized in Table 5. Estimated values of $\alpha$ and $\varphi$ deviate very slightly from their counterparts in Table 3. The parameter $\beta$ is not precisely estimated: only the estimated value of $\beta$ for $\tau=6$ (Reg. 5-3) has the expected positive sign and is significant. In this case, the estimate of $\beta$ is quite sensitive to the setting of the time interval $\tau$. The fact that the parameter $\beta$ is not precisely estimated plus that the estimated values are sensitive to the setting of the time interval $\tau$ may be due to a poor measurement of the provincial human capital stocks, or possibly due to a lagged effect of human capital formation on output, or simply due to too much multicollinearity between the explanatory variables in our regressions. We will come back to the issue of the linkage between human capital and TFP growth in the next section.

Table 4. Cross section regressions with human capital

\begin{tabular}{|c|c|c|c|c|c|c|}
\hline & \multicolumn{5}{|c|}{$\tau=1 \quad($ Obs: 261$)$} & $R^{2}=0.9625$ \\
\hline Parameter & Estimate & \multicolumn{2}{|c|}{$95 \%$ Conf. Interval } & Estimate & \multicolumn{2}{|c|}{$95 \%$ Conf. Interval } \\
\hline$\alpha$ & 0.529 & 0.471 & 0.587 & 0.532 & 0.474 & 0.591 \\
\hline$\beta$ & -0.028 & -0.081 & 0.025 & -0.028 & -0.081 & 0.025 \\
\hline$\varphi$ & -0.011 & -0.017 & -0.006 & -0.009 & -0.016 & -0.002 \\
\hline Coef. on $E$ & --- & --- & --- & 0.002 & -0.005 & 0.009 \\
\hline \multirow[t]{2}{*}{ Coef. on $W$} & --- & --- & --- & -0.002 & -0.008 & 0.004 \\
\hline & Reg. 4-2 & \multicolumn{2}{|c|}{$\begin{array}{c}\tau=3 \quad(\text { Obs: } 203) \\
R^{2}=0.5723\end{array}$} & Reg. 4-6 & \multicolumn{2}{|c|}{$R^{2}=0.5756$} \\
\hline Parameter & Estimate & \multicolumn{2}{|c|}{$95 \%$ Conf. Interval } & Estimate & \multicolumn{2}{|c|}{$95 \%$ Conf. Interval } \\
\hline$\alpha$ & 0.458 & 0.392 & 0.524 & 0.463 & 0.396 & 0.529 \\
\hline$\beta$ & -0.150 & -0.242 & -0.058 & -0.151 & -0.243 & -0.058 \\
\hline$\varphi$ & -0.037 & -0.050 & -0.023 & -0.029 & -0.047 & 0.011 \\
\hline Coef. on $E$ & --- & --- & --- & 0.009 & -0.009 & 0.027 \\
\hline \multirow[t]{2}{*}{ Coef. on $W$} & --- & --- & --- & -0.003 & -0.018 & 0.012 \\
\hline & Reg. 4-3 & \multicolumn{2}{|c|}{$\tau=6 \quad($ Obs: 116$)$} & Reg. 4-7 & \multicolumn{2}{|c|}{$R^{2}=0.5206$} \\
\hline Parameter & Estimate & \multicolumn{2}{|c|}{$95 \%$ Conf. Interval } & Estimate & \multicolumn{2}{|c|}{ 95\% Conf. Interval } \\
\hline$\alpha$ & 0.402 & 0.310 & 0.494 & 0.408 & 0.314 & 0.502 \\
\hline$\beta$ & -0.090 & -0.441 & 0.260 & -0.100 & -0.478 & 0.277 \\
\hline$\varphi$ & -0.073 & -0.101 & -0.045 & -0.061 & -0.100 & -0.021 \\
\hline Coef. on $E$ & --- & --- & --- & 0.014 & -0.025 & 0.052 \\
\hline \multirow[t]{2}{*}{ Coef. on $W$} & --- & --- & --- & -0.005 & -0.035 & 0.026 \\
\hline & Reg. 4-4 & \multicolumn{2}{|c|}{$\tau=9 \quad($ Obs: 29$)$} & Reg. $4-8$ & \multicolumn{2}{|c|}{$R^{2}=0.5829$} \\
\hline Parameter & Estimate & \multicolumn{2}{|c|}{$\frac{K}{95 \% \text { Conf. Interval }}$} & Estimate & \multicolumn{2}{|c|}{$95 \%$ Conf. Interval } \\
\hline$\alpha$ & 0.456 & 0.272 & 0.640 & 0.466 & 0.272 & 0.661 \\
\hline$\beta$ & -0.172 & -1.142 & 0.798 & -0.215 & -1.329 & 0.900 \\
\hline$\varphi$ & -0.101 & -0.183 & -0.019 & -0.073 & -0.191 & 0.045 \\
\hline Coef. on $E$ & --- & --- & --- & 0.027 & -0.086 & 0.140 \\
\hline Coef. on $W$ & --- & --- & --- & -0.014 & -0.102 & 0.074 \\
\hline
\end{tabular}


Table 5. Pooled cross section regressions with human capital and province dummies

\begin{tabular}{cccccc}
\hline & & $\tau=1$ & (Obs: 261$)$ & Reg. 5-1 & $R^{2}=0.9726$ \\
\hline Parameter & Estimate & & Std. Err. & \multicolumn{2}{c}{$95 \%$ Conf. Interval } \\
$\alpha$ & 0.555 & & 0.031 & 0.493 & 0.616 \\
$\beta$ & -0.027 & & 0.026 & -0.077 & 0.024 \\
$\varphi$ & 0.092 & & 0.031 & 0.030 & 0.154 \\
\hline Parameter & & $\tau=3$ & (Obs: 203) & Reg. 5-2 & $R^{2}=0.8292$ \\
$\alpha$ & Estimate & & Std. Err. & $95 \%$ Conf. Interval \\
$\beta$ & 0.493 & & 0.033 & 0.428 & 0.559 \\
$\varphi$ & -0.167 & & 0.045 & -0.256 & -0.077 \\
\hline & 0.604 & & 0.074 & 0.459 & 0.750 \\
\hline Parameter & & $\tau=6$ & (Obs: 116) & Reg. 5-3 & $R^{2}=0.9463$ \\
\hline$\alpha$ & Estimate & & Std. Err. & $95 \%$ Conf. Interval \\
$\varphi$ & 0.501 & & 0.042 & 0.416 & 0.586 \\
\hline & 0.260 & & 0.129 & 0.004 & 0.515 \\
\hline
\end{tabular}

\section{The Province Heterogeneity}

\subsection{Province Effect Indexes}

We have shown that conditional on the province-specific effects as picked up by the province dummy variables in the regressions in Tables 3 and 5, the 29 Chinese provinces exhibit clear conditional convergence in TFP growth over the sample period. Therefore, we are interested in seeing what factors underlie the province heterogeneity that may affect the rate of provincial TFP growth. Our analysis in the section is based on the estimated coefficients on the province dummies (i.e. the province intercepts) from the regressions in Table $3 .^{6}$ We specifically focus on the regression under $\tau=1$ because this regression has the largest adjusted R-squared (not reported in the table) compared with other regressions under alternative values of $\tau$. The (normalized) estimated province intercepts from this regression is listed in Table 6. We have normalized the intercept for Beijing to zero. We call these values of the province intercepts the 'province effect indexes'. The difference between the highest value of these indexes (Shanghai) and the lowest value (Sichuan) is roughly 0.22 .

\subsection{Province Effects versus Geographical Locations}

First we investigate how the province-specific effects are related to the geographical locations of the provinces. Regressing the province effect indexes on the two zone dummy variables $\mathrm{E}$ and $\mathrm{W}$, we find that the estimated coefficient on $\mathrm{E}$ is significantly positive, being 0.049 with a $95 \%$ confidence interval of $[0.015,0.083]$, and the estimated coefficient on W has the expected negative sign but is not significantly different from zero. This result of the simple exercise roughly shows that the expected value of the province effect index will be higher by about 0.05 for a coastal province than an inland province. Regressing the province effect indexes on $\mathrm{E}$ alone produces an even clearer picture: the estimated coefficient on $\mathrm{E}$ is now 0.060 with a $95 \%$ confidence interval of $[0.031,0.088]$. The $\mathrm{R}$-squared of this latter regression is 0.41 , showing that the zone dummy $\mathrm{E}$ alone explains over 40 percent of the sample variation in the province-specific effects. This result leads us to see that the eastern coastal provinces tend to have faster TFP growth over the sample period.

\footnotetext{
${ }^{6}$ We could as well use the estimated coefficients on the province dummies from the regressions in Table 5 because it has been shown that whether or not we have the human capital variables in the regression equation makes no significant difference as to the estimated values of the coefficients on the province dummies.
} 
Table 6. Calculated province effect indexes

\begin{tabular}{cccc}
\hline Province & effect index & Province & effect index \\
\hline Beijing & 0 & Henan & -0.0505 \\
Tianjin & 0.0562 & Hubei & -0.0108 \\
Hebei & 0.0067 & Hunan & -0.0249 \\
Shanxi & -0.0424 & Guangdong & -0.0033 \\
Inner Mongolia & 0.0037 & Guangxi & -0.0418 \\
Liaoning & 0.0936 & Sichuan & -0.1100 \\
Jilin & 0.0224 & Guizhou & -0.0733 \\
Heilongjiang & 0.0138 & Yunnan & 0.0046 \\
Shanghai & 0.1096 & Tibet & -0.0400 \\
Jiangsu & 0.0181 & Shannxi & -0.0195 \\
Zhejiang & 0.0097 & Gansu & -0.0332 \\
Anhui & -0.0093 & Qinghai & -0.0521 \\
Fujian & 0.0355 & Ningxia & -0.0032 \\
Jiangxi & -0.0346 & Xinjiang & -0.0207 \\
Shandong & -0.0042 & & \\
\hline
\end{tabular}

\subsection{Province Effects versus Human Capital}

Next, we are interested in seeing how the province-specific effects are related to the provinces' human capital stocks. We thus run a regression of the province effect indexes on the provinces' initial per worker human capital stocks (in logs) in 2003. The regression produces a significantly positive estimated coefficient on the latter, which is 0.178 with the $95 \%$ interval estimate being $[0.063,0.294]$. The R-squared of this regression is 0.27 , showing that the initial per worker human capital stock alone explains nearly 30 percent of the total sample variation in the province-specific effects. The sample correlation coefficient between the logs of the initial per worker human capital stocks and the province effect indexes is 0.52 .

\subsection{Province Effects versus Preferential Policy}

Since the province-specific effects are supposed to capture 'permanent' or stable geographical, social, institutional, and policy differences across the Chinese provinces, our conjecture is that relatively higher values of the province effect indexes for the coastal provinces are due to more exposure of these provinces to international economic activities such as foreign direct investment and foreign trade, which in turn rely heavily on the favorable geographical locations of these coastal provinces and the preferential policies they receive. Demurger et al. (2002) have constructed a set of preferential policy indexes for the Chinese provinces to study the effect of open-door preferential policies on provincial economic performance. ${ }^{7}$ We run a regression of the province effect index on the preferential policy index and find that the estimated coefficient on the latter is significantly positive, which is 0.035 with a $95 \%$ confidence interval of [0.013, 0.057]. ${ }^{8}$ The R-squared of this regression is 0.28 , showing that the provincial preferential policy index explains nearly 30 percent of the sample variation in the province-specific effects. Not surprisingly, this result suggests that open-door preferential policies (coupled with favorable geographical locations) of the eastern coastal provinces are conducive to TFP growth by enhancing the exposure of these provinces to foreign direct investment and foreign trade, which in turn facilitate technology spillovers.

\subsection{Social Infrastructure as the key Determinant of Human Capital Accumulation}

In addition, according to our analysis above, we strongly suspect that the province-specific factors embodied in the province effect indexes, i.e. the 'permanent' or stable geographical, social, institutional, and policy differences across the Chinese provinces, affect human capital accumulation in the provinces. This is in fact what the central idea of Hall and Jones (1999) is: differences in capital accumulation, productivity, and therefore output per worker are fundamentally related to differences in social infrastructure across economies. According to Hall and Jones (1999),

\footnotetext{
${ }^{7}$ Demurger et al. (2002) stress that their construction of the index is restricted to purely open-door preferential policies and does not take into account other factors, such as the business environment. They also point out that disentangling geography and policy is not an easy task because preferential treatments are obviously related to geography.

${ }^{8}$ See Table 11 of Demurger et al. (2002) for the values of the preferential policy indexes. The specific value for each province is calculated as the average of an evaluation of the province's preferential policy environment on a 0-3 scale for each of the years over 1978-1998. Therefore, the preferential policy index of Demurger et al. (2002) to a large extent reflects the stable or 'permanent' provincial preferential policy environment for the sample period of our analysis.
} 
social infrastructure refers to the institutions and government policies that determine the economic environment within which individuals accumulate skills, and firms accumulate capital and produce output. Therefore, as far as human capital is concerned, a social infrastructure favorable to high levels of output per worker should encourage educational attainment by ensuring that individuals capture the social returns to their education as private returns. A higher level of provincial educational attainment in turn facilitates provincial TFP growth by, for example, increasing the provincial absorptive capacity regarding foreign technology spillovers. ${ }^{9}$ Further studies on the relations between social infrastructure, human capital, and TFP growth for the Chinese provinces are on our future agenda.

\section{Concluding Remarks}

In this paper, we explore the characteristics of interregional TFP disparity in China and provide a related empirical analysis to enrich our understanding of the catch-up and convergence tendencies of the Chinese regions in terms of TFP. We build our baseline regression model on the basis of the Cobb-Douglas aggregate production function with Hicks-neutral TFP, where growth of per worker output is divided into growth of per worker capital accumulation and growth of TFP.

Our regression analysis fails to detect any absolute convergence in TFP across the Chinese provinces over the sample period. Provinces that had higher levels of TFP initially tended to experience faster growth in TFP over the sample period. However, after controlling for the province heterogeneity, our regression results show that the Chinese provinces exhibited significant conditional convergence in TFP growth. This indicates that province-specific factors play an important role in determining provincial TFP growth. The important policy implication of our regression results is that economic policies conducive to faster TFP growth should thus be directed to the relevant factors underlying the province heterogeneity.

We conjecture that relatively higher values of the province effect indexes for the coastal provinces are due to more exposure of these provinces to international economic activities such as foreign direct investment and foreign trade, which are dependent on the favorable geographical locations of these coastal provinces and the preferential policies they receive. Our empirical analysis accordingly suggests that open-door preferential policies coupled with favorable geographical locations of the eastern coastal provinces are conducive to TFP growth by enhancing the exposure of these provinces to foreign direct investment and foreign trade, which in turn facilitate technology spillovers.

As a byproduct, our regressions have shown a large (direct) contribution of physical capital accumulation to output growth.10 The regressions have all produced values of the output elasticity of physical capital $\alpha$ that are consistent with its empirically accepted values. In addition, although owing to imprecise estimations we have failed to show a direct contribution to output growth of human capital as an accumulable production input, our empirical analysis does suggest that human capital accumulation is associated with TFP growth: a higher level of provincial per worker human capital stock promotes provincial TFP growth by increasing the provincial absorptive capacity of technology diffusion from technologically advanced countries. Further studies on the linkage between the economic environment and policy, openness, human capital, and TFP growth for the Chinese provinces are on our future agenda.

\section{References}

Brandt, L., \& Zhu, X. (2010). Accounting for China's growth. Working Papers tecipa-394, Department of Economics, University of Toronto.

DaCosta, M., \& Carroll, W. (2001). Township and village enterprises, openness and regional economic growth in China. Post-communist Economist, 13(2), 229-241.

Demurger, S. (2001). Infrastructure development and economic growth: an explanation for regional disparity in China? Journal of Comparative Economics, 29(1), 95-117. http://dx.doi.org/10.1006/jcec.2000.1693

Demurger, S., Sachs, J., Woo, W. T., Bao, S., Chang, G., \& Mellinger, A. (2002). Geography, economic policy and regional development in China. Asian Economic Papers, 1(1), 146-197.

Fleisher, B., Li, H., \& Zhao, M. Q. (2010). Human capital, economic growth, and regional inequality in China. Journal of Development Economics, 92(2), 215-231. http://dx.doi.org/10.1016/j.jdeveco.2009.01.010

Hall, R. E., \& Jones, C. I. (1999). Why do some countries produce so much more output per worker than others? Quarterly Journal of Economics, 114(1), 83-116.

\footnotetext{
9 Prescott (1998) believes that the resistance to the efficient use of currently operating technologies and to the adoption of new technologies is an important factor that hinders TFP growth. Prescott's idea is compatible with the hypothesis that human capital is a crucial in determining the absorptive ability regarding foreign technology spillovers because better-educated workers have a comparative advantage in, and are thus less resistant to, the adoption of new technologies.

10 The ultimate cause of capital accumulation, however, may be TFP growth.
} 
Huang, J. T., Kuo, C. C., \& Kao, A. P. (2003). The inequality of regional economic development in China between 1991 and 2001. Journal of Chinese Economic and Business Studies, 1(3), 273-285.

http://dx.doi.org/10.1080/476828032000108553

Islam, N., \& Dai, E. (2007). Alternative estimates of TFP growth in China: Evidence from application of the dual approach. Working Paper Series Vol. 2007-03. The International Center for the Study of East Asian Development, Kitakyushu.

Jiang, Y. (2010). An empirical study of structural factors and regional growth in China. Journal of Chinese Economic and Business Studies, 8(4), 335-353. http://dx.doi.org/10.1080/14765284.2010.513173

Jiang, Y. (2011). Economic environment, technology diffusion, and growth of regional total factor productivity in China. Journal of Chinese Economic and Business Studies, 9(2), 151-161. http://dx.doi.org/10.1080/14765284.2011.568684

Jiang, Y. (2012). Technology diffusion, spatial effects and productivity growth in the Chinese provinces. International Review of Applied Economics, 26(5), 643-656. http://dx.doi.org/10.1080/02692171.2011.624498

Jiang, Y. (2014). Understanding TFP growth in inland regions of china: An empirical study of the effects of three factor. International Review of Applied Economics, 28(3), 364-381. http://dx.doi.org/10.1080/02692171.2013.872087

Kanbur, R., \& Zhang, X. (2005). Fifty years of regional inequality in China: A journey through central planning, reform, and openness. Review of Development Economics, http://dx.doi.org/10.1111/j.1467-9361.2005.00265.x

Krugman, P. (1994). The myth of Asia's miracle. Foreign Affairs, l73(6), 62-78.

Maddison, A. (1998). Chinese Economic Performance in the Long Run. Paris and Washington, D.C., Organization for Economic Co-operation and Development, 1998.

Mincer, J. (1974). Schooling, Experience, and Earnings. New York, Columbia University Press, 1974.

Prescott, E. C. (1998). Needed: A theory of total factor productivity. International Economic Review, 39(3), 525-551.

Psacharopoulos, G. (1994). Returns to investment in education: a global update. World Development, 22 , $1325-1343$.

Sachs, J. D., \& Woo W. T. (2000). Understanding China's economic performance. Journal of Policy Reform, 4(1), 1-50. http://dx.doi.org/10.1257/jep.26.4.103

Wan, G., Lu M., \& Chen Z. (2007). Globalization and regional income inequality: Empirical evidence from within China. Review of Income and Wealth, 53(1), 35-59. http://dx.doi.org/10.1111/j.1475-4991.2007.00217.x

World Bank. (1997). China 2020: Development Challenges in the New Century. Washington D.C., the World Bank, 1997.

Yang, D. T. (1999). Urban-biased policies and rising income inequality in China. American Economic Review Papers and Proceedings, 89(2), 306-310. http://dx.doi.org/10.1257/aer.89.2.306

Zhang, J., Wu G., \& Zhang J. (2007). Estimating China's provincial capital stock. Working Paper Series, China Center for Economic Studies, Fudan University.

Zhang, X. \& Zhang K. (2003). How does globalization affect regional inequality within a developing country? Evidence from China. Journal of Development Studies, 39(4), 47-67. http://dx.doi.org/10.1080/713869425

Zheng, J., \& Hu A. (2006). An empirical analysis of provincial productivity in China, 1979-2001. Journal of Chinese Economic and Business Studies, 4(3), 221-239. http://dx.doi.org/10.1080/14765280600991917

Zheng, J., Hu A., \& Bigsten A. (2009). Measuring potential output in a rapidly developing economy: The case of China in comparison with the US and EU. Federal Reserve Bank of St. Louis Review, July/August 2009, 317-342.

Zhu, S., Lai M., \& Fu X. (2008). Spatial characteristics and dynamics of provincial total factor productivity in China. Journal of Chinese Economic and Business Studies, 6(2), 197-217. http://dx.doi.org/10.1080/14765280802028328

\section{$(\mathrm{cc}) \mathrm{Br}$}

This work is licensed under a Creative Commons Attribution 3.0 License. 